\title{
Appropriate Thai High School Student Internet Behaviour: A Hierarchical Linear Model Analysis
}

\author{
https://doi.org/10.3991/ijet.v12i10.7366 \\ Punnee Leekitchwatana, Paitoon Pimdee $\left.{ }^{(}\right)$ \\ King Mongkut's Institute of Technology, Bangkok, Thailand \\ drpimdeekmitl@gmail.com
}

\begin{abstract}
The research used a hierarchical linear model to develop a model to study the variables of appropriate Internet use of 2,400 Thai high school students from 48 high schools. Furthermore, the groups were divided into one group of 1,200 students in science related programs, while the second group of 1,200 students were in a non-science related program. The data collection instrument was a reliability questionnaire which was determined to range between 0.75-0.97. Data were analysed using statistical averages, standard deviation, and analysis of hierarchical linear models (HLM). The research found that Thai high school students have appropriate Internet use behaviour at a very appropriate level, while the HLM of appropriate Internet use behaviour of students contained two predictive variables at both the student level and school level. These included the four student predictive variables of ability, characteristic, family, and student grade point average (GPA). At the school level in the HLM, there were two predictor variables including friends and schools, which had a direct influence and an indirect influence, respectively. There were also six capacity variables having both positive influence and statistical significance.
\end{abstract}

Keywords—behaviour, Internet use behaviour, learning management system (LMS), smart classrooms, Thailand

\section{Introduction}

In Thailand, of the 38 million Internet users, 8.7 million between the ages of $13-$ 19 use Facebook, with the average daily use of the Internet via a mobile smartphone now averaging 3 hours and 53 minutes per day [1]. The user activities on Facebook in Thailand are much higher than the global average with 19.8 million logging in every day.

Further evidence of the amazing rise in Thai Internet use is also confirmed by an October 2016 report in which YouTube Thailand was confirmed as being in the top position in Southeast Asia, which was additionally ranked in the top 10 in the world for YouTube users [2]. Thailand YouTube viewers also used their mobile devices for viewing $65 \%$ of the time, and on average spent 34 minutes on YouTube per visit, had 3.3 visits per day, and spent 1.9 hours on YouTube per day. 
Further confirmation of the importance of Internet use to Thailand's youth is the fact that when Internet use is broken out by age group, $15 \%$ are between $13-17$, while an amazing $45.6 \%$ of all Internet users in Thailand are between the ages of 19-24 [3].

A multitude of studies and scholars have also stressed the importance of the Internet and its plethora of devices and platforms, as tools in educating a 21 st Century workforce. Additionally, to realize the goals of a knowledge based economy under the objectives of Thailand 4.0 (Industry 4.0/Internet of Things) [4]-[6], scholars have emphasized the growing role of technology in education, and how students should use it to foster critical thinking skills, a key element of a 21st Century workforce [7]-[8].

Given the importance of the Internet on Thai youth and society, the researchers were therefore interested in building a casual model of appropriate Thai high school student Internet use behaviour. For this purpose, a HLM was chosen, as it has the advantage of allowing researchers to specify relations across multiple 'levels' of the educational system (e.g., students, classrooms, schools, etc. [9]. For the study, the levels selected included the student level and the school level. There were three predictor variables, including psychological (ability and characteristics), situation (family), and background (gender, Internet experience, grade point average, learning programs), which was based on a previous causal relationship model of Internet learning behaviour of lower secondary Thai school teachers [10]-[11].

\subsection{Statement of the problem}

Internet and social media use among Thai youth has exploded, especially in the age group between 13 and 24 years old [1]. Daily Internet usage rates continue to soar, with Thai youth spending nearly 4 hours a day using their smartphones to access Internet based social media. The question however, is this appropriate? Under Thailand 4.0, digital has been proclaimed to be the excelsior to a high quality of life [4], but just what is the cost to the student and the schools, and just what are the relationships between a student's learning ability, their gender, GPA, and family life? With these predictor variables in mind, the researchers strove to undertake an analysis of appropriate Thai high school student Internet behaviour by use of a HLM to study the above variables.

\section{$2 \quad$ Literature review}

\subsection{Dysfunctional Internet use (DIU)}

In research concerning dysfunctional Internet use (DIU) [12] indicated that two examples were Internet addiction (IA) and cyberbullying (CB), which frequently have negative outcomes, especially with younger and less conscientious individuals which are more likely to use the Internet dysfunctionally. This is supported by earlier research from Castiglione [13], in which it was determined that the Internet becomes a source of self-medication for younger users, especially to develop their identities or to 
establish relationships. Even if the Internet is used as a beneficial tool, abnormal use can have negative consequences for oneself and others over the long term [14].

\subsection{The Thai High School Internet user}

Creating an emotionally literate environment includes equipping students with essential life skills [15]. Research on teaching communication and collaboration skills encourages direct and mediated communication, working with others on team projects, and performance-based learning and assessment [16]. The Internet, and various learning management systems (LMS) platforms such as Moodle or Schoology accessed through the Internet, obviously fit these definitions [17]-[18]. The answer concerning the appropriateness of Internet use however, must be viewed within the context of how it is being used or abused.

Dečman used the Unified Theory of Acceptance and Use of Technology (UTAUT) [19] to evaluate E-learning systems and technologies in various educational environments, and determined that social influence and performance expectancy significantly influence the intention to use the technology. The research however found no significant influence of students' previous education or gender, with results suggesting that young people think that they handle modern technology well and are ready to use it if only an increase in performance is expected.

\subsection{High School Internet learning}

Research conducted on 1,179 elementary school students in an online science learning environment found that students who learn at home tend to spend more time learning, although they learn at a slower pace, but score higher than students who learn only in a school [20]. The results also suggest that neither age nor gender affect the differences found between school and home behaviours extending teaching time to the home by means of online learning environments is possible and worthwhile.

Technology is an enabler, and although some might disagree with the accuracy of its content, no one can disagree with how prolific Wikipedia has become, as in April 2017 Wikipedia had 5.4 million articles, 31 million users, and averages 800 new articles per day. In STEM (science, technology, engineering, and mathematics) online education, Khan Academy excels at what they do, and after starting as a single individual tutoring his niece online, has become an academy with 100 million users [21], having partnerships and sponsors with companies and organizations such as Google, Microsoft, and NASA.

A study of flipped education classrooms showed that video lectures outperform inperson lectures, with interactive online videos doing even better [22]. Online homework is just as effective as paper-and-pencil homework, and carefully developed intelligent tutoring systems have been shown to be just as effective as human tutors.

The issue therefore is not if online learning and Internet use by Thai high school students is effective; the question is how to manage and control the processes, tools, and devices that connect to it and other users. 


\subsection{The Hierarchical Linear Model}

From a synthesis of the research and theory, the following hierarchical linear model conceptual framework was established. The model shows the causal relationship diagram between the independent student and school variables as well as variables based on a student's proper internet usage [9]-[11].

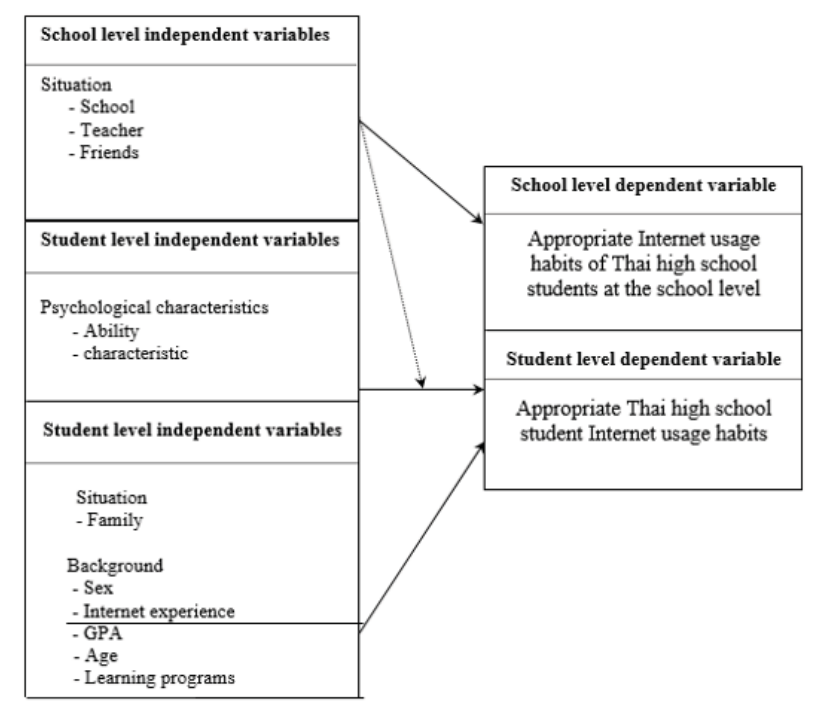

Fig. 1. Conceptual framework for a two-level, HLM of appropriate Internet use behaviour of Thai high school students

\section{Methodology}

\subsection{Population and sample}

The population of the study consisted of Thai high school students under the administration of the Office of the Basic Education Commission (OBEC). From this population and by use of multi-stage sampling, 50 students from each of 48 secondary/high school were selected. Of the 2,400-student sample group, this was further sub-divided into 2 groups, one group of 1,200 students in a science-focused program, with the second group of 1,200 , in a non-science focused program. From this a multistep, hierarchical linear model was developed to evaluate the appropriate Internet use behaviour of the two groups.

\subsection{Research tools}

The tools used to collect data were the appropriate Internet usage behaviour questionnaire and related information which used a 6-level agreement rating scale (Table 
1). The researchers created a comprehensive study from the independent and dependent variables, and modified it for the high school students' questionnaire on learning behaviour through electronic and related information.

The study's questionnaire variables consisted of 2 parts. These were:

Part 1 involved appropriate Internet use behaviour and consisted of 60 questionnaire items including three sub-areas. These were:

1. Teacher assigned Internet lessons.

2. Using the Internet to support learning in a variety of subjects.

3. Using the Internet to learn because it is free.

Ethical Internet use behaviour consisted of five sub-areas, including:

1. Not violating the privacy of others.

2. Not violating the other's ownership rights (copying).

3. Not abusing the public.

4. Protecting your channel from being infringed by others.

5. Being careful not to harm yourself.

Part 2 consisted of 103 items. These sections included the following topics:

1. Information about schools and teachers.

2. Information about home and family.

3. Information about friends.

4. Information about the student body which consisted of characteristics, ability, and a general student profile.

Table 1. Student comment scoring rubrics

\begin{tabular}{|l|c|c|}
\hline \multirow{2}{*}{\multicolumn{1}{|c|}{ Comments level }} & \multicolumn{2}{c|}{ Scoring Rubrics } \\
\cline { 2 - 3 } & Positive & Negative \\
\hline Most appropriate & 6 & 1 \\
\hline Very appropriate & 5 & 2 \\
\hline Moderately appropriate & 4 & 3 \\
\hline Less appropriate & 3 & 4 \\
\hline Minimally appropriate & 2 & 5 \\
\hline Not suitable & 1 & 6 \\
\hline
\end{tabular}

\subsection{Data analysis}

Questionnaire research validity verification was accomplished by use of the itemobjective congruence (IOC) [23]. Using the IOC, a try-out group of 56 students was used to initially evaluate question reliability. The scores ranged between $0.75-0.97$, from which an IOC score greater than 0.50 is considered acceptable, so the questionnaire items were deemed to be reliable. Descriptive statistics (mean $=\bar{x}$ and standard deviation $=\sigma$ ) were used to evaluate the quality of the HLM. Using the SPSS for Windows version 21 program, the $\bar{x}$ values criteria were as follows: 
Table 2. $\bar{x}$ value criteria

\begin{tabular}{|c|l|}
\hline Average range & \multicolumn{1}{c|}{ Behaviour level } \\
\hline $5.50-6.00$ & Most appropriate \\
\hline $4.50-5.49$ & Very appropriate \\
\hline $3.50-4.49$ & Moderately appropriate \\
\hline $2.50-3.49$ & Less appropriate \\
\hline $1.50-2.49$ & Minimally Appropriate \\
\hline $1.00-1.49$ & Not suitable \\
\hline
\end{tabular}

Analysis of the two-level linear gradients of appropriate internet use behaviour among Thai high school students was accomplished with the HLM 7 software program [24]. In the study, two types of models were defined whereupon three types of analysis were conducted [9], [25]. They were as follows:

Fully unconditional model - A two-level model of variables based on student's appropriate internet use. Part of the reason that HLM model building begins with an unconditional, or null model - is so that there is a baseline from which to compare the deviance statistic to for subsequent nested models [9].

Unconditional model - Predictors are entered at level 1 and include the introduction of the independent variables (student level) which is the same level as the dependent variable. From here a decision is made to only choose independent variables that influence the dependent variables according to statistical significance of $p$ value not more than 0.05 .

Hypothetical model - A two-level model which consisted of two independent predicative variables including student (level 1) and school (level 2).

Table 3 shows the criteria for interpretation of the predictive coefficient $\left(\mathrm{R}^{2}\right)$ of the independent variable series on the dependent variable in the unconditional model analysis, models with an independent variable at the student level, and hypothetical models (models with independent variables at the student level and at the school level(.

Table 3. Criteria for interpetation

\begin{tabular}{|c|c|c|}
\hline $\mathbf{R}^{\mathbf{2}}$ & $\mathbf{\%}$ & Level of prediction \\
\hline $\mathrm{R}^{2} \geq 0.49$ & from 49 up & high \\
\hline $0.09 \leq \mathrm{R}^{2}<0.49$ & from 9 but not to 49 & moderate \\
\hline $\mathrm{R}^{2}<0.09$ & less than 9 & Low \\
\hline
\end{tabular}

Table 4 results show that the appropriate Internet use behaviour among Thai high school students was overall very appropriate, both overall behaviour $\bar{x}=4.98$ and for both sides, sorted by average, the most important aspect is ethical Internet use behaviour $\bar{x}=5.30$, and Internet usage behaviour for learning $\bar{x}=4.83$. 
Table 4. Average, $\bar{x}, \sigma$, and rank of student behaviour

\begin{tabular}{|l|c|c|l|c|}
\hline \multirow{2}{*}{\multicolumn{1}{|c|}{ Appropriate Internet use behaviour }} & \multicolumn{2}{|c|}{$\boldsymbol{n = \mathbf { 2 , 4 0 0 }}$} & \multirow{2}{*}{ Importance Level } & Rank \\
\cline { 2 - 5 } & $\bar{x}$ & $\boldsymbol{\sigma}$ & & \\
\hline Internet usage behaviour for learning. & 4.83 & 0.50 & very appropriate & 2 \\
\hline Teacher assigned Internet lessons. & 4.59 & 0.75 & very appropriate & 3 \\
\hline Using the Internet to support learning in a variety of subjects. & 4.94 & 0.65 & very appropriate & 1 \\
\hline Using the Internet to learn because it is free. & 4.79 & 0.54 & very appropriate & 2 \\
\hline Ethical Internet use behaviour. & 5.30 & 0.82 & very appropriate & 1 \\
\hline Not violating the privacy of others. & 5.22 & 0.72 & very appropriate & 2 \\
\hline Not violating the other's ownership rights (copying). & 5.41 & 0.73 & very appropriate & 1 \\
\hline Not abusing the public. & 4.91 & 0.82 & very appropriate & 5 \\
\hline Protecting your channel from being infringed by others. & 5.01 & 0.76 & very appropriate & 4 \\
\hline Being careful not to harm yourself. & 5.17 & 0.62 & very appropriate & 3 \\
\hline Total & 4.98 & 0.51 & very appropriate & - \\
\hline
\end{tabular}

\section{$4 \quad$ Results}

The results of the two-tier, hierarchical linear model analysis of appropriate internet use behaviour among Thai high school students, consisted of 3 models using 2 levels of analysis. These included a model for the dependent variable, a model with the independent variables showing the student level, and a model with the independent variables that included both the student level and the school level. Details are presented in Tables 57 and Figure 2.

\subsection{Model for dependent variables}

Results from the modelling the behaviour of the dependent variable of appropriate Internet student use in Table 5 shows the full unconditional model of appropriate Internet behaviour habits used by Thai high school students.

Table 5. Analysis of variables based on appropriate Internet use behaviour

\begin{tabular}{|c|c|c|c|c|c|}
\hline \multicolumn{1}{|c|}{ Fixed Effect } & Coefficient & $\begin{array}{c}\text { Standard } \\
\text { error }\end{array}$ & t-ratio & $\begin{array}{c}\text { Approx. } \\
\text { d.f. }\end{array}$ & $\boldsymbol{p}$ value \\
\hline For INTRCPT1, $\beta 0$ & \multicolumn{5}{|l|}{} \\
\hline INTRCPT2, $\gamma 00$ & 4.98 & 0.03 & 191.61 & 47 & $<0.001$ \\
\hline Random Effect & $\begin{array}{c}\text { Standard } \\
\text { Deviation }\end{array}$ & $\begin{array}{c}\text { Variance } \\
\text { Component }\end{array}$ & d.f. & $\chi \mathbf{2}$ & $\boldsymbol{p}$ value \\
\hline INTRCPT1, u0 & 0.17 & 0.03 & 47 & 323.96 & $<0.001$ \\
\hline level-1, r & 0.48 & 0.24 & & & \\
\hline
\end{tabular}

Analytical results from the fixed effects by t-test found constant (INTRCPT), of the appropriate Internet use behaviour of all students in the school or total mean had a positive influence on the variables based on appropriate Internet use behaviour 
(BEHAVIOUR) of students within the school to have a value of 4.98, which is different from at the statistical significance level of $<0.001$ (Table 5).

1. Analytical results from the random effects by testing chi-square $(\chi 2$-test) found that the average variable rate based on the appropriate Internet use behaviour of students had a significant difference between schools at the statistically significant level of $<0.001$, with a variance component $=0.03$.

Results showed that appropriate student Internet use behaviour was different among schools, having a variance $=0.24$, with a total variance of all observations at 0.26 . Furthermore, it can be interpreted that the major variance is between students $(89.46 \%)$, while differences between schools had a variance of only $10.54 \%$. Also, the independent variables can be used to explain variance at the student level and school level, so analysis of the models with independent variables was carried out.

\subsection{Models for independent variables at the student level}

Models with independent variables at the student level consisted of models with variable behaviour of high school students using the Internet appropriately as the dependent variable. There are also independent variables at the student level in level 1 as well, with the predictive variables being statistically significant. The model looks like an unconditional model, with the results of the analysis shown in Table 6.

Results in Table 6 and Figure 2 show the fixed effects and random effects of the independent variables at the student level as follows:

1. Analytical results of the models with independent variables at the student level were conducted by use of t-test, which found that constants (INTRCPT), had an average score of appropriate internet use behaviour among school children, which also included 4 independent variables including ability (ABILITY), characteristic (AFFECT), family (FAMILY) and the student's GPA (GPA). At the student level, there was also a positive influence on the variables based on appropriate Internet use behaviour of students at the statistical significance level 0.01 , with constant $=$ 4.967 , and the variable regression coefficients of ability, characteristic (AFFECT), family and student GPA being $0.350,0.138,0.115$, and 0.029 , respectively. This explains the variance of student appropriate Internet use behaviour at a high level with $57.55 \%$.

2. Analytical results of the random effects by use of chi-square ( $\chi 2$-test) testing found constant and 4independent variables to have a significant variance at the school level, with a statistical significance of $<0.001$. Constant value, the remaining variance $=0.00601$ and ability (ABILITY), characteristic (AFFECT), family (FAMILY) and the student's GPA (GPA), had variance $=0.014,0.023,0.008$, and 0.00278 , respectively. This shows the variables based on the student's appropriate Internet use habits and the coefficient of regression of the predictor variables of these four student level variables can be used to explain the independent variables at the school level. 
Paper-Appropriate Thai High School Student Internet Behaviour: A Hierarchical Linear Model Analysis

Table 6. Analysis of models with independent variables at the student level

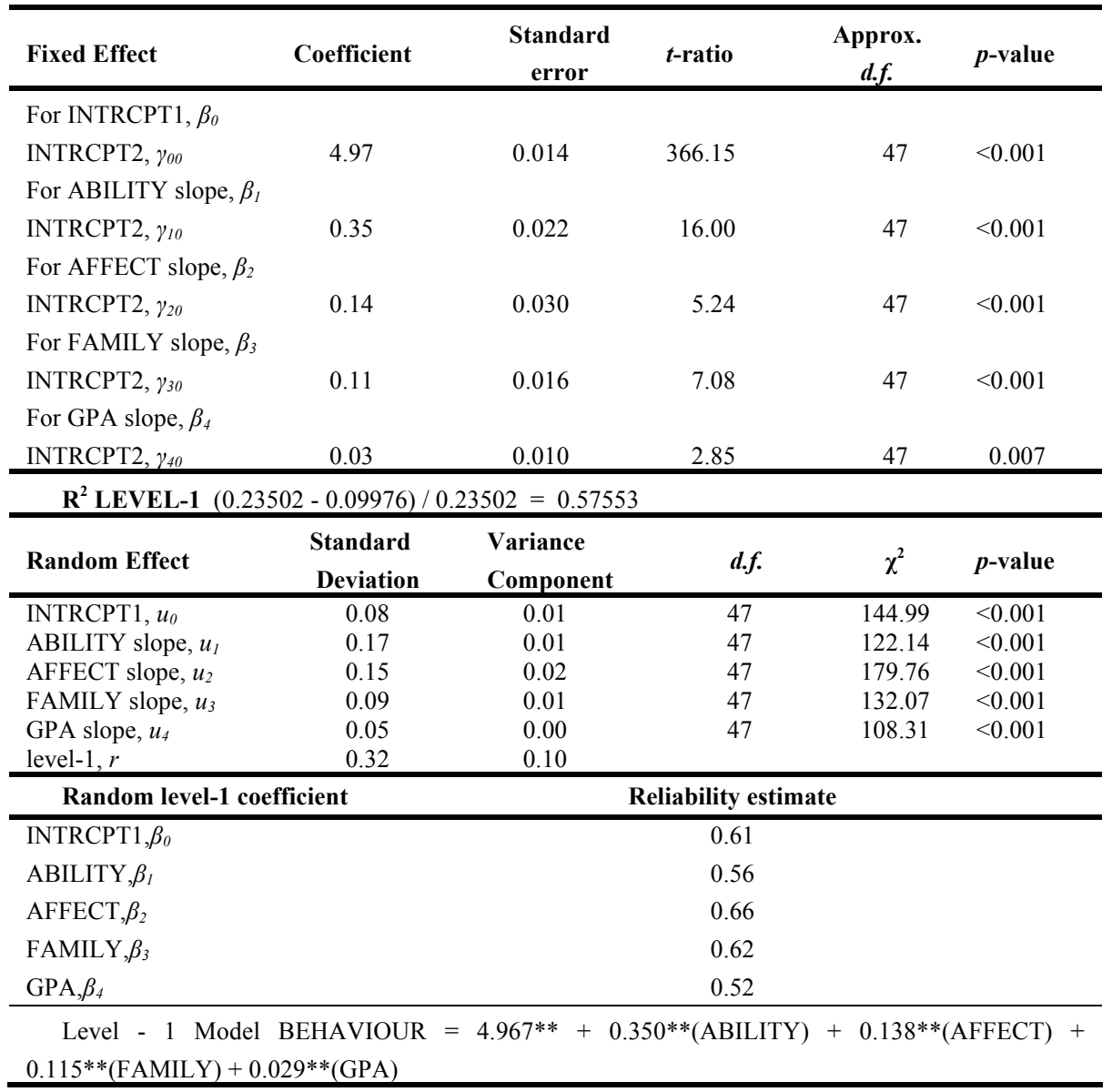

\subsection{Models for independent variables at both the student and school level}

Models with independent variables at the student level and school level used the variable of high school students using the Internet appropriately as the dependent variable. There were also independent variables at the student level and school level as well. The results of the analysis are shown in Table 7 and Figure 2. 
Paper-Appropriate Thai High School Student Internet Behaviour: A Hierarchical Linear Model Analysis

Table 7. Analysis of models with independent variables at the student level and school level

\begin{tabular}{|c|c|c|c|c|c|}
\hline Fixed Effect & Coefficient & $\begin{array}{l}\text { Standard } \\
\text { error }\end{array}$ & $t$-ratio & $\begin{array}{c}\text { Approx. } \\
\text { d.f. }\end{array}$ & $p$-value \\
\hline \multicolumn{6}{|l|}{ For INTRCPT1, $\beta_{0}$} \\
\hline INTRCPT $2, \gamma_{00}$ & 4.96 & 0.01 & 446.69 & 46 & $<0.001$ \\
\hline FRIEND, $\gamma_{01}$ & 0.23 & 0.04 & 5.15 & 46 & $<0.001$ \\
\hline \multicolumn{6}{|l|}{ For ABILITY slope, $\beta_{l}$} \\
\hline INTRCPT2, $\gamma_{10}$ & 0.35 & 0.02 & 16.55 & 46 & $<0.001$ \\
\hline SCHOOL, $\gamma_{11}$ & 0.07 & 0.03 & 2.19 & 46 & 0.034 \\
\hline \multicolumn{6}{|l|}{ For AFFECT slope, $\beta_{2}$} \\
\hline INTRCPT2, $\gamma_{20}$ & 0.14 & 0.03 & 5.63 & 47 & $<0.001$ \\
\hline \multicolumn{6}{|l|}{ For FAMILY slope, $\beta_{3}$} \\
\hline \multicolumn{5}{|l|}{ For GPA slope, $\beta_{4}$} & $<0.001$ \\
\hline INTRCPT $2, \gamma_{40}$ & 0.03 & 0.01 & 2.64 & 47 & 0.011 \\
\hline
\end{tabular}

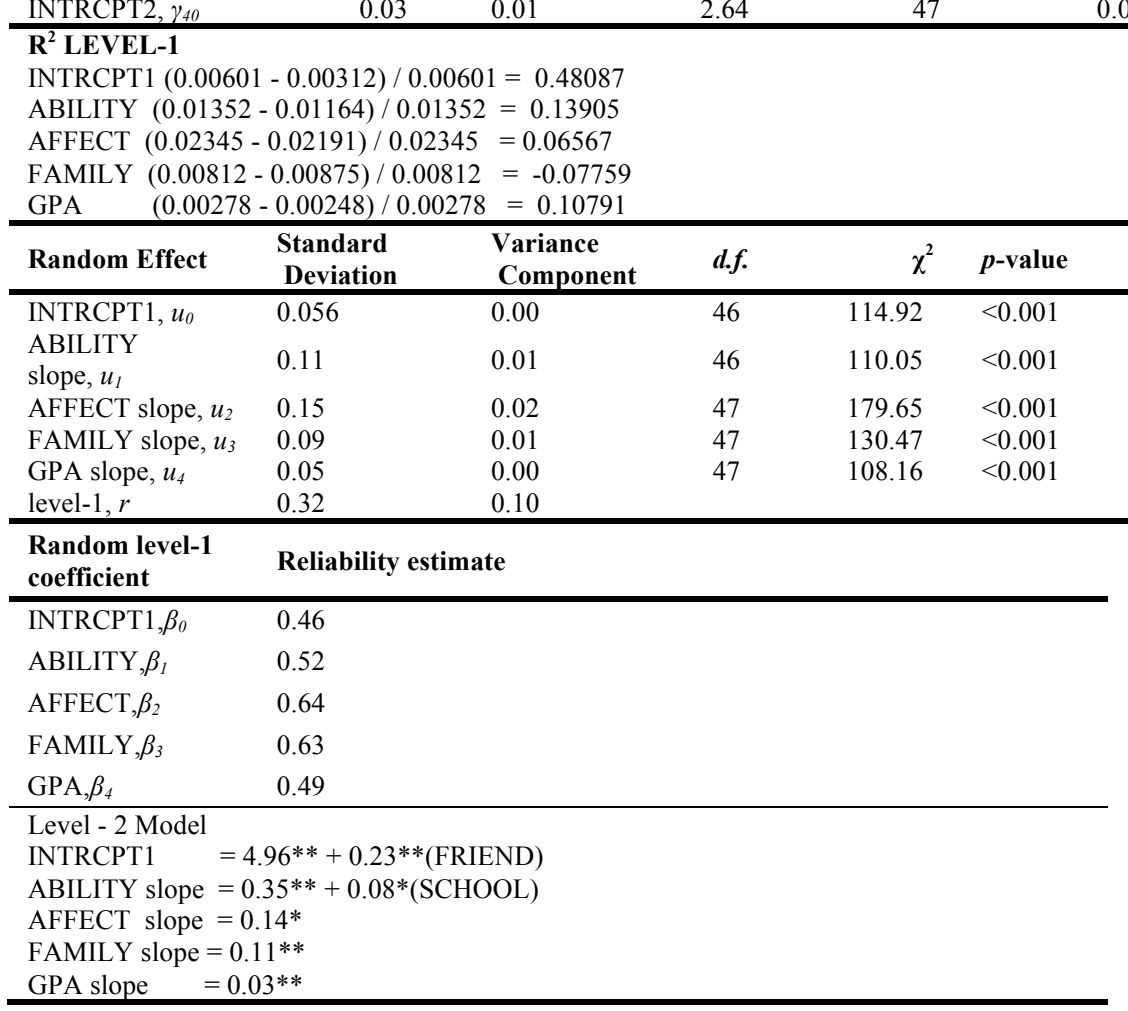

Table 7 and Figure 2 show the results of the fixed effects and random effects as follows:

1. Analytical results of the fixed effects were conducted by use of t-test which found that constants (INTRCPT), of school students or total mean and one independent variable at the school level is friends (FRIEND). It has a positive influence on the behaviour of the dependent variable of appropriate Internet use at the school level with a statistical significance level of 0.01 . The constant of the school-level analysis $=4.96$, which also has a regression coefficient of the friend variable $=0.23$. The 
mean variance of the average of appropriate Internet behaviours of school students was at a moderate level at $48.09 \%$. For regression coefficients of variables, ability (ABILITY), characteristic (AFFECT), family (FAMILY), and the student's GPA (GPA), have a constant value of $=0.35,0.14,0.11$, and 0.03 respectively. Additionally, there is 1independent variable at the school level which is the school variable. Regression coefficient describes the ability (ABILITY $=13.91 \%)$ at the statistically significant level of 0.05 . There are regression coefficients of the school variables $=0.07$.

2. Analytical results of the random effects were conducted by use of chi-square $\left(\chi^{2}\right)$ test and found that constants and four independent variables had a significant variance at the school level at the statistically significant level of 0.01 . By constant value, the remaining variance $=0.00$, with the variables ability (ABILITY), characteristic (AFFECT), family (FAMILY), and student GPA (GPA) having a remaining variance equal to $0.01,0.02,0.01$, and 0.00 , respectively. Figure 2 shows the 9 variables' results from the HLM are statistically significant at the 2nd level. This included 4 variables at the student level, which included ability (ABILITY) $(b=0.347)$, characteristic (AFFECT) $(b=0.144)$, family (FAMILY) $(b=0.108)$, and student GPA (GPA) $(b=0.026)$, as well as 2 variables at the school level, which included friends (FRIEND) $(b=0.23)$ and school $(\mathrm{SCHOOL})(b=0.08)$.

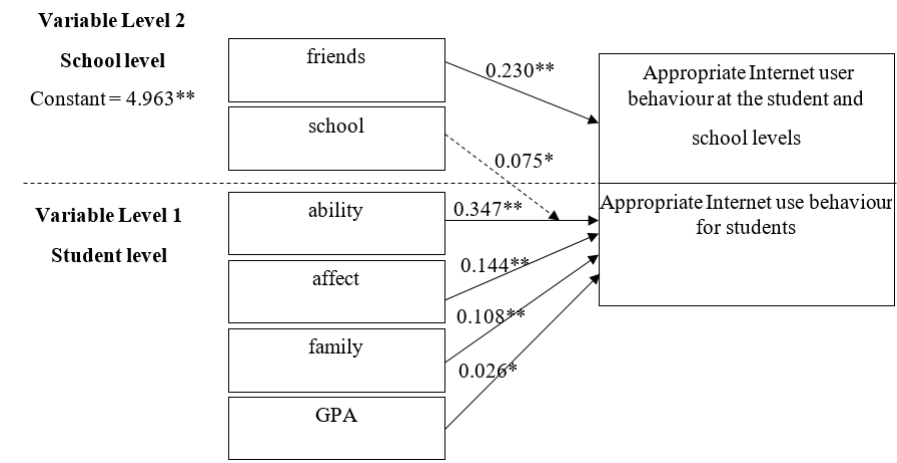

Fig. 2. HLM of the two levels of appropriate Internet use behaviour of Thai high school students

\section{Discussion}

HLM was used in this study for the following reasons [25]:

1. HLM is used to account for the nested data structure encountered in meta-analyses.

2. HLM also allows for estimation of the mean of the underlying effect size distribution

3. HLM also provides an estimate for the variance of effect-size parameters, and residual variance, and uses information from all studies to obtain an empirical Bayes estimate of each study's effect. 


\subsection{The appropriate level of Internet use behaviour of students}

From the 2,400 students evaluated, both the students in science related programs and those in non-science related programs were found to have appropriate Internet use behaviour at the most appropriate level. In addition, when considering individual behaviour, it was found that both behaviour in the use of the Internet for learning, and ethical Internet use were at a high level as well. These findings are consistent with the research from [11], [20], [26]-[28].

\subsection{HLMs of the appropriate Internet use behaviour of students}

Appropriate Internet use behaviour of students was positively influenced by $6 \mathrm{pre-}$ dictive variables at a significant level, which consisted of two levels of variables. At the student level, there were 4 variables and at the school level, 2 variables There were 3types of variables within 2students, and 3variables outside the student body and 1 background variable. Both levels have a common influence on students' proper use of the internet, with student's behaviour being appropriate, depending on the six variables, which were ranked from moderate to high.

Of the six predictor variables, 4 variables were at the student level which included, ability (ABILITY) $b=0.347$, characteristics (AFFECT) $b=0.144$, family (FAMILY) $\mathrm{b}=0.108$, and the student's GDP (GFP). $\mathrm{b}=0.026$. At the school-level, there were 2 variables including friends (FRIEND) $b=0.230$, and school (SCHOOL) $b=0.075$. These results are consistent with research from [20], [26]-[29].

This is consistent with other Thai education HLM research results [10], in which it was determined that information technology (IT) use behaviour of high school teachers was composed of 2 levels of predictor variables, which were the teacher level and school level. In the mixed model, predictors at teacher level were ability, affection, and income, with each variable having a positive influence on behaviour.

Because of the analysis of random effects in the hypothetical model, it was found that the variance of the mean variance was based on the Internet use behaviour of the Thai high school students at both the school level and the student level which remained high. This variable can also support additional predictive variables, which can explain more variance in this variable. In addition, the coefficient of regression of the predictor variable of ability (ABILITY), characteristic (AFFECT), family (FAMILY) and the student's GPA (GPA), there is still variability as well. Thus, it can accommodate additional predictive variables as well as behavioural variables.

\section{Suggestions}

1. Educational policymakers at all levels need to focus on the development of school readiness, educational personnel (both administrators and teachers), and can continuously develop appropriate student Internet use behaviour [30]-[31].

2. Schools need to be physically ready. This includes computer labs, highperformance Internet networks, smart classrooms, and having personnel capable of promoting appropriate Internet use. There must all be a mechanism to improve and 
motivate ethical Internet use. In addition, parents should communicate with their children about the importance of appropriate Internet use. However, if a local communities and families have limited ability to lend support, the school must take on the role of supporting the students. This includes giving students the opportunity to use the Internet at school, which is best served by a smart classroom arrangement, Internet related activities and projects.

3. Teachers should improve teaching quality by assigning tasks that can lead to ethical Internet use behaviour by giving advice and allowing students to use Internet resources. This also entails fair assessments of student work, while providing constructive feedback to students. Teachers should provide a learning experience through the Internet in a way that provides opportunities for students and their peers to interact with each other, such as collaborative learning and STEM Education [32]. In addition, Internet learning habits should be developed which includes learning attitudes, Internet use and reading habits, orientation and control, and achievement motivation [5].

4. The student's family should also be aware of and support student Internet learning and use of Internet capable devices including home computers and smartphones.

5. The student should focus on self-improvement and have the ability for selflearning, while being aware of the proper and ethical use of the Internet. Students should also build relationships with friends in promoting mutual learning, and collaborate with others in assisting them in their learning abilities.

\section{$7 \quad$ Acknowledgments}

This research was funded by National Research Council of Thailand. The research team would like to thank them for the opportunity and research interest. Additionally, further support for this research was kindly given by the King Mongkut's Institute of Technology Ladkrabang and the Faculty of Industrial Education and Technology. In addition, the authors thank the many schools and students under the Office of the Basic Education Commission (OBEC) which participated in the research as well.

\section{$8 \quad$ References}

[1] We are social. (2016). Digital in 2016. [Online]. Available: http://tinyurl.com/k3udrtl

[2] A. Pornwasi. (2016, October 12). Thailand is still number one for YouTube viewers in Southeast Asia. The Nation. [Online]. Available: http://tinyurl.com/y8ozg88d

[3] M. Vichienwanitchkul. (2015, January 13). Online Marketing Thailand: The State of Social Media. [Online]. Available: http://tinyurl.com/kdgezjb

[4] C. Jones and P. Pimdee, "Innovative ideas: Thailand 4.0 and the Fourth Industrial Revolution," Asian International Journal of Social Sciences, Vol 17 No 1 pp. 4 - 35, 2016. [Online]. Available: http://tinyurl.com/lw8a5cn

[5] P. Phuapan, C. Viriyavejakul and P. Pimdee, "An analysis of digital literacy skills among Thai university seniors," International Journal of Emerging Technologies in Learning, Vol 11 No 3, 2016. https://doi.org/10.3991/ijet.v11i03.5301 
[6] E. M. Reeve, "21st century skills needed by students in technical and vocational education and training (TVET)". Asian International Journal of Social Sciences. Vol 16 No 4, pp. $65-82,2018$. [Online]. Available: http://tinyurl.com/z97ypfc

[7] National Education Association. (2011). Preparing 21st century students for a global society. [Online]. Available: http://tinyurl.com/mttg8wz

[8] OECD/UNESCO. (2016). Education in Thailand: An OECD-UNESCO Perspective. Reviews of National Policies for Education, Paris: OECD Publishing. [Online]. Available: from http://tinyurl.com/ml6nufq

[9] D. Anderson, Hierarchical linear modeling (HLM): An introduction to key concepts within cross-sectional and growth modeling frameworks. Eugene, OR: Behavioural Research and Teaching, 2012. [Online]. Available: http://tinyurl.com/muunlng

[10] P. Leekitchwatana, "Development of hierarchical linear model information technology use behaviour of secondary school teacher in Thailand". European Journal of Social Sciences, Vol 32 No 4, pp. 554-566, 2012.

[11] P. Leekitchwatana, "Development of causal relationship model of learning behaviour via internet of lower secondary students in Bangkok metropolis". Mediterranean Journal of Social Sciences, Vol 4 No 4, pp. 39-53, 2013. https://doi.org/10.5901/mjss.2013.v4n4p39

[12] B. Stodt, E. Wegmann, E. and M. Brand, "Predicting dysfunctional Internet use: The role of age, conscientiousness, and Internet literacy in Internet addiction and cyberbullying". International Journal of Cyber Behaviour, Psychology and Learning, Vol 6 No 4, 2016. https://doi.org/10.4018/IJCBPL.2016100103

[13] J. Castiglione "Internet abuse and possible addiction among undergraduates: A developing concern for library and university administrators". Library Review, Vol 57 No 5, pp. 358371, 2008. https://doi.org/10.1108/00242530810875140

[14] Guan, S. S. and Subrahmanyam, K. "Youth Internet use: risks and opportunities". Current Opinions in Psychiatry, Vol 4, pp. $351-356,2009$. doi: 10.1097/YCO.0b013e32832bd7e0.

[15] K. C. Williams and C. C. Williams, "Five key ingredients for improving student motivation". Research in Higher Education Journal, Vol 11, 2011. [Online]. Available: http://tinyurl.com/zzc6en8

[16] Partnership for $21^{\text {st }}$ Century Learning. (2017). [Online]. Available: http://www.p21.org/

[17] W. Banyen, C. Viriyavejakul and T. Ratanaolarn, "A Blended Learning Model for Learning Achievement Enhancement of Thai Undergraduate Students". International Journal of Emerging Technologies in Learning, Vol 11 No 4, 2016. https://oi.org/10.3991/ijet.v11i04.5325

[18] I. Blau and M. Hameirie, "Implementing technological change at schools: The impact of online communication with families on teacher interactions through learning management system". Interdisciplinary Journal of E-Learning and Learning Objects. Vol 6 No 1, pp. 245-257, 2010. [Online]. Available: http://tinyurl.com/162yho8

[19] M. Dečman, "Modeling the acceptance of e-learning in mandatory environments of higher education: The influence of previous education and gender". Computers in Human Behaviour, Vol 49, pp. 272-281, 2015.

[20] G. Ben-Zadok, M. Leiba and R. Nachmias, "Comparison of online learning behaviours in school vs. at home in terms of age and gender based on log file analysis". Interdisciplinary Journal of E-Learning and Learning Objects. Vol 6 No 1, pp. 305-322, 2010. [Online]. Available: http://tinyurl.com/lwsdagn

[21] Skoll Foundation. (2015). Khan Academy. [Online]. Available:http://tinyurl.com/myavrlv

[22] J. L. Bishop and M. A. Verleger, The Flipped Classroom: A Survey of the Research, 2013. [Online]. Available: http://tinyurl.com/k46unee 
[23] R. K. Hambleton, "Validating the test score," in A guide to criterion-referenced test construction. Baltimore: Johns Hopkins University Press, 1984.

[24] Scientific Software International. HLM - Hierarchical Linear and Nonlinear Modeling (HLM), 2016. [Online]. Available: http://www.ssicentral.com/hlm/

[25] S. W. Raudenbush and A. S. Bryk, Hierarchical Linear Models: Applications and Data Analysis Methods (2 ${ }^{\text {nd }}$ ed.). Newbury Park, CA: Sage, 2002.

[26] L. M. O'Dwyer, M. Russell and D. Bebell, "Identifying teacher, school, and district characteristics associated with middle and high school teachers' use of technology: A multilevel perspective". Journal of Educational Computing Research. Vol 33 No. 4, pp. 369393, 2005.

[27] R. G. Saadé, X. He and D. Kira, "Exploring dimensions to online learning", Computers in Human Behaviour. Vol 23 No 4, pp. 1721-1739, 2007.

[28] K.-S. Hong, "Relationship between students' and instructional variables with satisfaction and learning from a Web-based course". Internet and Higher Education, Vol 5, pp. 267281, 2002. https://doi.org/10.1016/S1096-7516(02)00105-7

[29] A., Tarhini, K. Hone, and X. Liu, "Factors affecting students' acceptance of e-learning environments in developing countries: A structural equation modeling approach". International Journal of Information and Education Technology. Vol 3 No 1, pp. 54-59, 2013.

[30] K. Shapley, D. Sheehan, C. Maloney and F. Caranikas-Walker, "Effects of technology immersion on teachers' growth in technology competency, ideology, and practices". Journal of Educational Computing Research. Vol 42 No 1, pp. 1-33, 2010.

[31] R. Yilmaz, "Exploring the role of e-learning readiness on student satisfaction and motivation in flipped classroom". Computers in Human Behaviour. Vol 70, pp. 251-260, 2017.

[32] J. A., Paul, H. M., Baker, \& J. D. Cochran, "Effect of online social networking on student academic performance". Computers in Human Behaviour, Vol 28 No 6, pp. 2117-2127, 2012. https://doi.org/10.1016/j.chb.2012.06.016

\section{Authors}

Punnee Leekitchwatana is an Associate Professor in the Department of Industrial Education at the King Mongkut's Institute of Technology Ladkrabang (KMITL), Bangkok, Thailand. She graduated with a B.Ed. and M.Ed. in science education and has a Ph.D. in research and curriculum development. She specializes in education research, science education, curriculum development and measurement/evaluation education.

Paitoon Pimdee is an Associate Professor with the Faculty of Industrial Education and Technology at the King Mongkut's Institute of Technology Ladkrabang (KMITL), Bangkok, Thailand. He also serves has the faculty head of the PhD program, and the head of the Department of Industrial Education. He graduated with a Bachelor of Arts in Economics and a Master of Science (M.Sc.) degree in science education. He also holds a Ph.D. in environmental education and behavioural sciences and specializes in environmental issues, energy conservation, and ecotourism.

Article submitted 28 June 2017. Published as resubmitted by the authors 30 August 2017. 